20

\title{
Выявление путей гибели клеток карциномы почки человека А498 под действием экстракта аврана лекарственного и флавоноидов зеленого чая с помощью флуоресцентных методов визуализации
}

\author{
(ㄷ А.М. Мыльников ${ }^{1}$, Н.В. Полуконова ${ }^{1}$, Д.С. Исаев ${ }^{1}$, А.А. Дорошенко ${ }^{2}$, Р.А. Верховский ${ }^{1}$, \\ Н.А. Николаева ${ }^{1}$, Д.А. Мудрак ${ }^{1}$, Н.А. Наволокин ${ }^{1}$ \\ ${ }^{1}$ Саратовский ГМУ им. В.И. Разумовского Минздрава РФ, \\ 440012 Саратов, Россия \\ ${ }^{2}$ Саратовский национальный исследовательский государственный университет им. Н.Г. Чернышевского, \\ 440012 Саратов, Россия \\ e-mail: artyom-mylnikov@mail.ru
}

Поступила в редакцию 11.12.2019 г.

В окончательной редакции 17.02.2020 г.

Принята к публикации 28.02.2020 г.

С использованием флуоресцентных методов визуализации апоптоза и некроза в опухолевых клетках человека in vitro сравнивались эффективности противоопухолевого воздействия на клетки карциномы почки человека A498 флавоноидсодержащих экстрактов: аврана лекарственного и зеленого чая в сверхнизких концентрациях через 24 и 48 h. Флуоресцентные красители (йодистый пропидий и акридиновый оранжевый) использовались в тесте „живые и мертвые“, что позволило выявлять общее количество погибших клеток путем некроза и апоптоза, а также клеток, в которых запустился апоптоз, при этом выявлялись апоптотические тельца или пикноз ядра. Наиболее выраженной цитостатической активностью через $48 \mathrm{~h}$ после воздействия обладал экстракт аврана, уменьшая количество клеток в поле зрения в 1.5 раза по сравнению с контролем. Наиболее выраженной цитотоксической активностью обладал экстракт зеленого чая в концентрации $0.0288 \mathrm{mg} / \mathrm{ml}$, и выраженность ее нарастала через $48 \mathrm{~h}$ после воздействия. Экстракт аврана проявлял цитотоксическую активность при более низких концентрациях $(0.0036 \mathrm{mg} / \mathrm{ml})$.

Ключевые слова: флуоресцентные методы визуализации, противоопухолевая активность, клеточная культура, цитостатическая активность, флавоноиды, рак почки, авран лекарственный.

DOI: $10.21883 /$ OS.2020.07.49569.72-20

\section{Введение}

Онкологические заболевания по данным ВОЗ в 2018 г. занимают второе место в структуре смертности в мире и РФ. Используемые в терапии опухолевых процессов химиопрепараты цитостатического действия на основе алкалоидов не обладают избирательной активностью и имеют множество побочных эффектов. Механизм воздействия цитостатиков на клетку основывается на двух точках приложения: они связываются с нитями веретена деления на стадии метафазы или на стадии подготовки к делению, разрушают топоизомеразу во время репликации ДНК, что приводит к остановке клеточного цикла, и клетка гибнет путем некроза. В результате гибели подвергаются любые пролиферирующие клетки организма. Одним из побочных эффектов такого воздействия является развитие интоксикации под влиянием продуктов распада (эндотоксинов) некротизированной клетки [1].

Для решения данной проблемы необходим поиск новых лекарственных средств, оказывающих целевое воздействие на опухолевые клетки и косвенно снижающих уровень эндогенной интоксикации в результате уменьшения некроза нормальных пролиферирую- щих клеток организма. С точки зрения физиологии наиболее благоприятным и естественным для клетки является прекращение ее жизнедеятельности путем апоптоза, который является генетически запрограммированным вариантом клеточной гибели, таким образом обеспечивается тканевый гомеостаз. Однако на данный момент отсутствует широкое внедрение противоопухолевых препаратов с апоптотическим механизмом действия в терапию опухолевых процессов, поскольку возможность их применения была открыта относительно недавно, и на данный момент большинство из них находится на стадии доклинических и клинических исследований.

Существуют различные методики визуальной оценки клеток, находящихся на различных этапах своего развития. Основным преимуществом классических методов флуоресцентной микроскопии является возможность изучения не только фиксированных клеток, но и живых, а также исследование их микроструктуры. Несмотря на то что флуоресцентная микроскопия имеет более низкое разрешение по сравнению с электронной или атомносиловой микроскопией, она в отличие от последних оказалась оптимальным методом для изучения меха- 
низмов функционирования организмов на клеточном, субклеточном и молекулярном уровнях $[2,3]$.

Разработка нового лекарственного средства начинается с исследований in vitro, что позволяет сделать более экономичным и эффективным первичный скрининг [4].

Кроме того, методы in vitro более гуманны, так как сокращают количество животных, используемых в исследованиях [5].

Возможность флуоресцентных методов визуализировать живые клетки и относительная простота применения в лабораторных условиях делают данные методы наиболее приемлемыми для исследований in vitro [6].

Одним из передовых направлений в клеточной биологии при разработке новых лекарственных препаратов является изучение программируемой клеточной гибели (ПКГ) — основного механизма элиминации клеток из организма как в нормальных условиях, так и при патологии. В настоящее время выделяют 12 видов ПГК, однако наиболее распространенными являются апоптоз, аутофагия, кератинизация и некроз. Активация апоптоза считается одним из самых перспективных механизмов действия противоопухолевых препаратов.

С морфологической точки зрения апоптоз - это форма гибели клетки, при которой происходит конденсация хроматина с последующим образованием отдельных апоптотических телец, покрытых мембраной, без выхода содержимого клетки в окружающую среду. Согласно биохимическому подходу - это каскад взаимодействия различных каспаз (ферментов) [7]. Одним из преимуществ апоптоза по сравнению с некрозом является тот факт, что при гибели путем апоптоза не развивается интоксикация, и клетка умирает без негативных последствий для организма.

Признаком ПКГ при использовании флуоресцентной микроскопии служит обнаружение ярко светящегося конденсированного хроматина. Применение флуоресцентных способов окраски с использованием двойного окрашивания акридиновым оранжевым и йодистым пропидием в тесте „живые и мертвые“ дает возможность выявлять общее количество погибших клеток, а также дифференцировать их в зависимости от механизма гибели. При этом подвергшиеся некрозу клетки окрашивались в красный цвет, с развившимся апоптозом - в зеленый цвет. При этом в клетках, в которых запустился апоптоз, выявлялись апоптотические тельца или пикноз ядра (также окрашенные в зеленый цвет). Следовательно, флуоресцентная микроскопия может служить одним из методов скрининговой оценки эффективности различных фармакологических препаратов [8].

Флавоноиды обладают широким спектром биологической активности, в том числе и способностью активировать апоптоз. Так, известно, что катехин (галлатэпигаллокатехин) флавоноидов экстракта зеленого чая обладает тремя основными механизмами противоопухолевой активности: антипролиферативным, торможением фазы G1 подготовки клетки к делению и механизмом индукции апоптоза $[9,10]$. Экстракт зеленого чая получают из измельченных листьев зеленого неферментированного чая Camellia sinensis - род вечнозеленых кустарников или деревьев семейства чайных. При изготовлении зеленого чая листья нагревают для инактивации ферментов, подвергают скручиванию, потом подсушивают до 50\% влажности, затем еще раз скручивают и после этого высушивают. Для приготовления сухого экстракта зеленого чая листья измельчают, экстрагируют водой, полученный жидкий экстракт отстаивают, очищают и концентрируют, затем густой экстракт высушивают [11]. Многочисленными исследованиями доказана эффективность зеленого чая в комбинированном лечении рака молочной железы, рака предстательной железы, рака шейки матки, опухолей мочевого пузыря, рака печени [12]. Основными противоопухолевыми агентами зеленого чая в настоящее время признаны эпикатехин-3-галлат и эпигаллокатехин-3-галлат. Их действие реализуется на нескольких этапах канцерогенеза: они нарушают трансдукцию - передачу сигнала внутри опухолевой клетки, тормозя пролиферацию опухолевых клеток; активируют апоптоз опухолевых клеток; уменьшают экспрессию фактора роста эндотелия (VEGF) и блокируют ангиогенез в опухолевой ткани. Таким образом, катехины зеленого чая ингибируют рост опухоли, нарушают ее питание и распространение [12].

Экстракт аврана был получен способом, позволяющим снижать токсичность и повышать выход флавоноидов из растительного сырья, обладает противоопухолевым, антикахетическим и иммуномодулирующим действиями. Способ получения сухого экстракта из растительного сырья включает измельчение травы аврана лекарственного, экстракцию спиртом 96\%, выпаривание экстракта, добавление хлороформа, удаление хлороформа. Экстракцию спиртом проводят на водяной бане до кипения и кипятят в течение 14-15 min, выпаривают при температуре $55-60^{\circ} \mathrm{C}$, выпаренный экстракт разводят сначала дистиллированной водой $40-50^{\circ} \mathrm{C}$, затем добавляют хлороформ в пропорции 4/5 части воды и $1 / 5$ части хлороформа, охлаждают до комнатной температуры и центрифугируют со скоростью 1500 оборотов в минуту в течение $15 \mathrm{~min}$, далее отделяют водную фракцию и высушивают ее [13]. Исследования противоопухолевой активности проводились на моделях перевиваемых опухолей крысам в экспериментах in vivo (рака печени, рака почки и саркомы [14-18]) и экспериментах in vitro [1921] в отношении клеток эмбриона почки свиньи, рака шейки матки HeLa, рака почки и рака молочной железы человека. Результаты исследований позволили описать механизмы воздействия на опухоль и опухолевые клетки: остановка клеточного цикла на стадии Go, запуск апоптоза, индуцированного геном р53 и подавление цитопротекторной аутофагии [22,23].

Несмотря на выявленные пути ингибирования канцерогенеза, ранее не было проведено расчетов оптимальных дозировок для данных веществ и не было исследовано влияние сверхнизких концентраций на ме- 
ханизмы клеточной гибели клеток карциномы почки человека А498.

Цель исследования - с использованием флуоресцентных методов визуализации апоптоза и некроза в опухолевых клетках человека in vitro выявить пути гибели клеток карциномы почки человека А498 под действием флавоноидсодержащих экстрактов аврана лекарственного и зеленого чая в сверхнизких концентрациях через 24 и $48 \mathrm{~h}$.

\section{Материал и методы}

Объектом исследования послужили клетки карциномы почки A498, полученные из банка опухолевых культур РОНЦ им. Н.Н. Блохина, Москва.

В исследовании использованы вещества с предполагаемой противоопухолевой активностью: экстракт зеленого чая (катехины и полифенолы), экстракт аврана лекарственного (флавоноиды) в следующих концентрациях $(\mathrm{mg} / \mathrm{ml}): 0.0018,0.0036,0.0072,0.0144,0.0288,0.0576$, $0.1152[11]$.

Культивирование клеток проводили в пластиковых флаконах в среде RPMI4 (10\% эмбриональной сыворотки, ампициллина, пирувата натрия, глутамина) в $\mathrm{CO}_{2}$-инкубаторе при $37^{\circ} \mathrm{C}$ в течение 24 и $48 \mathrm{~h}$. Затем клетки, находящиеся в пластиковых флаконах, рандомизированным способом были разделены на группы: контрольную группу (без воздействия) и экспериментальные группы (с воздействием сверхнизких концентраций экстрактов аврана лекарственного и зеленого чая). После этого клетки окрашивали. В качестве красителей использовали йодистый пропидий (проникающий в нежизнеспособные клетки за счет разрушения их мембраны) и акридиновый оранжевый для окрашивания живых клеток.

Для визуализации клеток использовали микроскоп Nikon (Токио, Япония). Захват и анализ изображений проводили с помощью цифровой видеокамеры Nikon (разрешение $2560 \times 1920$ ). Для подсчета клеток использовали программное обеспечение FijilmageJ и NIS-ElementsBR 4.60.

Для анализа цитотоксической, цитостатической и апоптотической активностей сравнивали в контрольной и экспериментальной группах следующие показатели: количество клеток в поле зрения (СКК); количество мертвых клеток в поле зрения; количество живых клеток в поле зрения; количество делящихся клеток; количество клеток с признаками апоптоза (апоптотические тельца, пикноз ядра, хроматин в виде „серпов““).

Статистическую обработку проводили в программе SPSSStatistics 17.0. Нормальность распределения признака по группам оценивали с помощью критерия ШапироУилка. Было выявлено, что распределение признаков не соответствует нормальному, в связи с чем для оценки достоверности отличий от контрольной группы был использован непараметрический критерий Манна-Уитни.

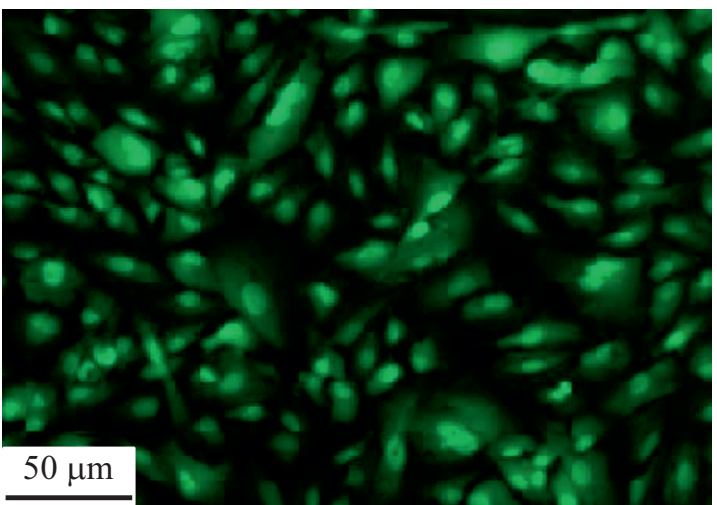

Рис. 1. Клетки культуры A498 через $24 \mathrm{~h}$, окраска живых клеток акридиновым оранжевым. Обьектив $\times 20$.

В группах определяли медиану, 25-й и 75-й квартили, максимальное и минимальное значения. Различия принимали за достоверные на уровне значимости $p<0.05$.

\section{Результаты}

При воздействии на клетки карциномы почки А498 исследуемых экстрактов в сверхнизких концентрациях через $24 \mathrm{~h}$ наблюдалось большое количество клеток различной формы, что связано с развитием изменений в них. Через $48 \mathrm{~h}$ картина была аналогичной. Клетки в контрольной группе имели овальную форму, что свидетельствует о том, что клетки прикреплены к подложке и жизнеспособны (рис. 1).

В ходе проведения флуоресцентной микроскопии через $24 \mathrm{~h}$ установлено увеличение общего количества клеток по сравнению с контрольной группой при воздействии экстракта аврана лекарственного в концентрациях $0.0018,0.0036,0.0144,0.0576 \mathrm{mg} / \mathrm{ml}$. Экстракт зеленого чая оказывал такой же эффект только при наибольших концентрациях - 0.0036, $0.0576 \mathrm{mg} / \mathrm{ml}$ (табл. 1). Полученные данные напрямую взаимосвязаны с увеличением количества живых клеток, что свидетельствует об увеличении пролиферативной активности клеток рака почки под действием экстрактов в сверхнизких концентрациях через $24 \mathrm{~h}$ после воздействия.

При воздействии экстрактом аврана количество мертвых клеток достоверно увеличивается в 2 раза по сравнению с контролем только при концентрации $0.0288 \mathrm{mg} / \mathrm{ml}$.

Количество клеток рака почки с ядрами в виде серпов и апоптотическими тельцами увеличивалось под действием экстракта аврана по сравнению с контролем только при концентрации $0.0018 \mathrm{mg} / \mathrm{ml}$. Однако количество клеток с пикнозом ядра, свидетельствующим о подготовке клеток к апоптозу, при всех концентрациях было выше контрольных значений, составляя до 30\% от общего количества клеток в поле зрения (рис. 2).

При воздействии экстрактом зеленого чая количество мертвых клеток увеличивается при концентраци- 
Таблица 1. Морфологические показатели клеток культуры рака почки А498, полученные с помощью флуоресцентных методов визуализации через $24 \mathrm{~h}$ после воздействия экстрактами аврана лекарственного и зеленого чая (медиана (квартиль 25-квартиль 75) [минимум-максимум])

\begin{tabular}{|c|c|c|c|c|c|c|c|c|}
\hline \multirow{2}{*}{ Показатели } & \multirow{2}{*}{ Контроль } & \multicolumn{7}{|c|}{ Концентрации, mg/ml } \\
\hline & & 0.0018 & 0.0036 & 0.0072 & 0.0144 & 0.0288 & 0.0576 & 0.1152 \\
\hline \multicolumn{9}{|c|}{ Экстракт Аврана лекарственного } \\
\hline $\begin{array}{l}\text { Количество клеток } \\
\text { в поле зрения }\end{array}$ & $\begin{array}{c}133 \\
(112- \\
143.5) \\
{[112-148]}\end{array}$ & $\begin{array}{c}179.5^{*} \\
(160.5- \\
192.5) \\
{[156-200]}\end{array}$ & $\begin{array}{c}151.5^{*} \\
(144.75- \\
158.5) \\
{[141-172]} \\
\end{array}$ & $\begin{array}{c}139 \\
(126- \\
176.5 \\
{[123-187]} \\
\end{array}$ & $\begin{array}{c}154 \\
(139- \\
172) \\
{[133-179]} \\
\end{array}$ & $\begin{array}{c}148 \\
(138.75- \\
183.75) \\
{[132-186]} \\
\end{array}$ & $\begin{array}{c}167^{*} \\
(151- \\
172) \\
{[150-173]} \\
\end{array}$ & $\begin{array}{c}147.5 \\
(139- \\
159.75) \\
{[131-171]} \\
\end{array}$ \\
\hline $\begin{array}{l}\text { Количество } \\
\text { мертвых клеток в } \\
\text { поле зрения }\end{array}$ & $\begin{array}{c}2 \\
(0.75- \\
4.25) \\
{[0-5]} \\
\end{array}$ & $\begin{array}{c}3.5 \\
(2- \\
5.25) \\
{[2-9]} \\
\end{array}$ & $\begin{array}{c}3.5 \\
(0.75- \\
6.75) \\
{[0-12]} \\
\end{array}$ & $\begin{array}{c}3 \\
(1- \\
4) \\
{[1-4]}\end{array}$ & $\begin{array}{c}3.5 \\
(2.75- \\
5.75) \\
{[2-8]} \\
\end{array}$ & $\begin{array}{l}4.5^{*} \\
(3.5- \\
5.25) \\
{[2-6]} \\
\end{array}$ & $\begin{array}{c}2.5 \\
(1.75- \\
7.25 \\
{[1-8]} \\
\end{array}$ & $\begin{array}{c}1 \\
(2- \\
5.25 \\
{[0-3]} \\
\end{array}$ \\
\hline $\begin{array}{l}\text { Количество живых } \\
\text { клеток в поле } \\
\text { зрения }\end{array}$ & $\begin{array}{c}130.5 \\
(108.75- \\
135) \\
{[108-148]}\end{array}$ & $\begin{array}{c}176^{*} \\
(156- \\
189.75) \\
{[147-198]}\end{array}$ & $\begin{array}{c}137 \\
(128.75- \\
147) \\
{[128-153]}\end{array}$ & $\begin{array}{c}136.5 \\
(124.25- \\
173) \\
{[119-185]}\end{array}$ & $\begin{array}{c}151 \\
(132- \\
167) \\
{[130-176]}\end{array}$ & $\begin{array}{c}143 \\
(136.25- \\
179.5) \\
{[128-181]}\end{array}$ & $\begin{array}{c}162.5^{*} \\
(146- \\
169) \\
{[143-172]}\end{array}$ & $\begin{array}{c}145 \\
(136.75- \\
159.5) \\
{[130-170]}\end{array}$ \\
\hline $\begin{array}{l}\text { Количество клеток } \\
\text { с серпами }\end{array}$ & $\begin{array}{c}2 \\
(1.75- \\
4.25) \\
{[1-5]} \\
\end{array}$ & $\begin{array}{c}7^{*} \\
(5.75- \\
10.75) \\
{[5-16]} \\
\end{array}$ & $\begin{array}{c}3.5 \\
(2.75- \\
7.25) \\
{[2-8]} \\
\end{array}$ & $\begin{array}{c}2 \\
(1- \\
3.25) \\
{[1-4]} \\
\end{array}$ & $\begin{array}{c}2 \\
(0- \\
3) \\
{[0.75-2.25]} \\
\end{array}$ & $\begin{array}{c}2.5 \\
(1.75- \\
3.25) \\
{[1-4]} \\
\end{array}$ & $\begin{array}{c}3.5 \\
(2.75- \\
5.25) \\
{[2-6]} \\
\end{array}$ & $\begin{array}{c}2.5 \\
(1.75- \\
3.5) \\
{[0-5]} \\
\end{array}$ \\
\hline $\begin{array}{l}\text { Количество клеток } \\
\text { с пикнозом ядра }\end{array}$ & $\begin{array}{c}2.5 \\
(0.75- \\
4) \\
{[0-4]} \\
\end{array}$ & $\begin{array}{c}8^{*} \\
(6.75- \\
13) \\
{[6-16]}\end{array}$ & $\begin{array}{c}195^{*} \\
(14.25- \\
28.25) \\
{[12-35]}\end{array}$ & $\begin{array}{c}25^{*} \\
(22.5- \\
30.75) \\
{[21-33]}\end{array}$ & $\begin{array}{c}26^{*} \\
(22- \\
28) \\
{[11-30]}\end{array}$ & $\begin{array}{c}23^{*} \\
20.5 \\
27.75) \\
{[19-30]}\end{array}$ & $\begin{array}{c}30^{*} \\
(26- \\
39) \\
{[20-45]}\end{array}$ & $\begin{array}{c}29.5^{*} \\
(19.75- \\
34) \\
{[19-40]}\end{array}$ \\
\hline $\begin{array}{l}\text { Количество клеток } \\
\text { с апоптотическим } \\
\text { тельцами }\end{array}$ & $\begin{array}{c}1 \\
(0-3.5) \\
{[0-8]}\end{array}$ & $\begin{array}{c}5 \\
(2.75-28.5) \\
{[2-45]}\end{array}$ & $\begin{array}{c}0.5 \\
(0-2.75) \\
{[0-5]} \\
\end{array}$ & $\begin{array}{c}2 \\
(0.75-3.25) \\
{[0-4]}\end{array}$ & $\begin{array}{c}1 \\
(0.75-2) \\
{[0-2]}\end{array}$ & $\begin{array}{c}1.5 \\
(0-2.25) \\
{[0-3]}\end{array}$ & $\begin{array}{c}1 \\
(1-1) \\
{[1-1} \\
\end{array}$ & $\begin{array}{c}1 \\
(0-1) \\
{[1-1]}\end{array}$ \\
\hline \multicolumn{9}{|c|}{ Экстракт зеленого чая } \\
\hline $\begin{array}{l}\text { Количество клеток } \\
\text { в поле зрения } \\
\text { (СКК) }\end{array}$ & $\begin{array}{c}133 \\
(112- \\
143.5) \\
{[112-148]} \\
\end{array}$ & $\begin{array}{c}138 \\
(117.5- \\
170.5) \\
{[107-172]} \\
\end{array}$ & $\begin{array}{c}160.5^{*} \\
(134.25- \\
201.75) \\
{[129-207]} \\
\end{array}$ & $\begin{array}{c}153 \\
(115- \\
166.75) \\
{[103-178]} \\
\end{array}$ & $\begin{array}{c}160 \\
(152- \\
164.75 \\
{[146-170]} \\
\end{array}$ & $\begin{array}{c}122.5 \\
(82.25- \\
167.75 \\
{[71-182]} \\
\end{array}$ & $\begin{array}{c}162^{*} \\
(155.5- \\
184.5 \\
{[154-201]} \\
\end{array}$ & $\begin{array}{c}148 \\
(141.75- \\
162.25) \\
{[132-166]} \\
\end{array}$ \\
\hline $\begin{array}{l}\text { Количество } \\
\text { мертвых клеток в } \\
\text { поле зрения }\end{array}$ & $\begin{array}{c}2 \\
(0.75- \\
4.25) \\
{[0-5]} \\
\end{array}$ & $\begin{array}{c}3.5 \\
(2.75- \\
5.25) \\
{[2-6]} \\
\end{array}$ & $\begin{array}{c}7.5^{*} \\
(6-13) \\
{[3-19]} \\
\end{array}$ & $\begin{array}{c}4.5 \\
(2.75-5 \\
{[2-5]} \\
\end{array}$ & $\begin{array}{c}9^{*} \\
(6.75- \\
10.5) \\
{[6-12]} \\
\end{array}$ & $\begin{array}{c}4 \\
(1.5-5) \\
{[0-5]} \\
\end{array}$ & $\begin{array}{l}7.5^{*} \\
(4.5- \\
11.25) \\
{[3-12]} \\
\end{array}$ & $\begin{array}{c}5.5^{*} \\
(4.75- \\
7.5) \\
{[4-9]} \\
\end{array}$ \\
\hline $\begin{array}{l}\text { Количество живых } \\
\text { клеток в поле } \\
\text { зрения }\end{array}$ & $\begin{array}{c}130.5 \\
(108.75- \\
130.5) \\
{[108-148]} \\
\end{array}$ & $\begin{array}{c}134 \\
(113.75- \\
167) \\
{[104-167]} \\
\end{array}$ & $\begin{array}{c}145.5 \\
(128.25- \\
194) \\
{[126-200]} \\
\end{array}$ & $\begin{array}{c}149.5 \\
(110.5- \\
162) \\
{[100-174]} \\
\end{array}$ & $\begin{array}{c}152 \\
(140.5- \\
157) \\
{[136-163]} \\
\end{array}$ & $\begin{array}{c}118 \\
(77.5- \\
167.25) \\
{[67-180]} \\
\end{array}$ & $\begin{array}{c}155 \\
(144.75- \\
179.25) \\
{[144-195]} \\
\end{array}$ & $\begin{array}{c}140.5 \\
(131.25- \\
157) \\
{[123-160]} \\
\end{array}$ \\
\hline $\begin{array}{l}\text { Количество клеток } \\
\text { с серпами клеток }\end{array}$ & $\begin{array}{c}2 \\
(1.75- \\
4.25) \\
{[1-5]} \\
\end{array}$ & $\begin{array}{c}1.5^{*} \\
(0.75-5.5) \\
{[0-7]} \\
\end{array}$ & $\begin{array}{c}3.5 \\
(1.5-5.5) \\
{[0-7]} \\
\end{array}$ & $\begin{array}{c}4.5^{*} \\
(2.75- \\
6.75) \\
{[2-9]} \\
\end{array}$ & $\begin{array}{c}5.5 \\
(1.75- \\
7.25) \\
{[1-8]} \\
\end{array}$ & $\begin{array}{c}2 \\
(0.75-4) \\
{[0-4]} \\
\end{array}$ & $\begin{array}{c}3 \\
(1-6.75) \\
{[1-9]} \\
\end{array}$ & $\begin{array}{c}2 \\
(1.75- \\
3.75) \\
{[1-6]} \\
\end{array}$ \\
\hline $\begin{array}{l}\text { Количество клеток } \\
\text { с пикнозом ядра }\end{array}$ & $\begin{array}{c}2.5 \\
(0.75-4) \\
{[0-4]} \\
\end{array}$ & $\begin{array}{c}6.5^{*} \\
(4-8.75) \\
{[4-14]} \\
\end{array}$ & $\begin{array}{c}2.5 \\
(0-5) \\
{[0-5]} \\
\end{array}$ & $\begin{array}{c}3.5 \\
(3-4.25) \\
{[3-5]} \\
\end{array}$ & $\begin{array}{c}4.5 \\
(2.75-6) \\
{[2-6]} \\
\end{array}$ & $\begin{array}{c}4 \\
(2.25-5) \\
{[0-5]} \\
\end{array}$ & $\begin{array}{c}5^{*} \\
(1.75-7.5) \\
{[1-9]} \\
\end{array}$ & $\begin{array}{c}4 \\
(3.75-5.25) \\
{[3-6]} \\
\end{array}$ \\
\hline $\begin{array}{l}\text { Количество клеток } \\
\text { с апоптотическими } \\
\text { тельцами }\end{array}$ & $\begin{array}{c}1 \\
(0-3.5) \\
{[0-8]}\end{array}$ & $\begin{array}{c}0 \\
(0-0.25) \\
{[0-1]}\end{array}$ & $\begin{array}{c}0 \\
(0-0) \\
{[0-0]}\end{array}$ & $\begin{array}{c}0 \\
(0-0.25) \\
{[0-1]}\end{array}$ & $\begin{array}{c}0 \\
(0-0.25) \\
{[0-1]}\end{array}$ & $\begin{array}{c}0 \\
(0-0.25) \\
{[0-1]}\end{array}$ & $\begin{array}{c}0 \\
(0-4.5) \\
{[0-6]}\end{array}$ & $\begin{array}{c}0.5 \\
(0-4.5) \\
{[0-6]}\end{array}$ \\
\hline
\end{tabular}

Примечание. * Достоверность различий между контрольной и экспериментальной группами, рассчитанная при помощи критерия Манна-Уитни, $p<0.05$. 
Таблица 2. Морфологические показатели клеток культуры рака почки А498. полученные с помощью флуоресцентных методов визуализации через $48 \mathrm{~h}$ после воздействия экстрактами аврана лекарственного и зеленого чая (медиана (квартиль 25-квартиль 75) [минимум-максимум])

\begin{tabular}{|c|c|c|c|c|c|c|c|c|}
\hline \multirow{2}{*}{ Показатели } & \multirow{2}{*}{ Контроль } & \multicolumn{7}{|c|}{ Концентрации, mg/ml } \\
\hline & & 0.0018 & .0036 & 0.0072 & 0.0 & 0.0288 & 0.0576 & 0.1152 \\
\hline \multicolumn{9}{|c|}{ Экстракт Аврана лекарственного } \\
\hline $\begin{array}{l}\text { зо клеток } \\
\text { ения }\end{array}$ & $\begin{array}{c}155.5 \\
(137.5- \\
167.5) \\
{[133-169]}\end{array}$ & $\begin{array}{c}123^{*} \\
(102.75- \\
132.25) \\
{[102-136]}\end{array}$ & $\begin{array}{c}133.5 \\
(125.75- \\
138.75) \\
{[119-141]}\end{array}$ & $\begin{array}{c}112^{*} \\
(82.25- \\
118.75) \\
{[77-124]}\end{array}$ & $\begin{array}{c}91.5^{*} \\
(73.75- \\
107.25) \\
{[61-117]}\end{array}$ & $\begin{array}{c}103^{*} \\
(96.75- \\
130) \\
{[93-139]}\end{array}$ & $\begin{array}{c}84^{*} \\
(74-103) \\
{[65-112]}\end{array}$ & $\begin{array}{c}101.5^{*} \\
(87.25- \\
111) \\
{[70-114]}\end{array}$ \\
\hline $\begin{array}{l}\text { гво } \\
\text { клеток в } \\
\text { ния }\end{array}$ & $\begin{array}{c}5.5 \\
(3.5-6.75) \\
{[2-9]}\end{array}$ & $\begin{array}{c}4 \\
(1.75-7.5) \\
{[1-9]}\end{array}$ & $\begin{array}{c}10.5^{*} \\
(4.75-21.75) \\
{[4-27]}\end{array}$ & $\begin{array}{c}6^{*} \\
(4.75-7.25) \\
{[4-8]}\end{array}$ & $\begin{array}{c}10^{*} \\
(8.5-18) \\
{[7-21]}\end{array}$ & $\begin{array}{c}18 \\
(4.75-25.5 \\
{[4-33]}\end{array}$ & \begin{tabular}{|c|}
4 \\
$(1.75-9.75$ \\
{$[1-12]$}
\end{tabular} & $\begin{array}{c}4.5 \\
(2-13.5 \\
{[2-18]}\end{array}$ \\
\hline $\begin{array}{l}\text { живых } \\
\text { оле }\end{array}$ & $\begin{array}{c}149.5 \\
(136.25- \\
165) \\
{[128-165]} \\
\end{array}$ & $\begin{array}{c}118.5^{*} \\
(96.75- \\
118.5) \\
{[96-135]}\end{array}$ & $\begin{array}{c}122^{*} \\
(107-133) \\
{[92-136]} \\
\end{array}$ & $\begin{array}{c}104.5^{*} \\
(77- \\
114.25) \\
{[71-118]}\end{array}$ & $\begin{array}{c}83.5^{*} \\
(53.75- \\
96.75) \\
{[44-108]} \\
\end{array}$ & $\begin{array}{c}86 \\
(78.5- \\
120.5) \\
{[65-122]} \\
\end{array}$ & $\begin{array}{c}68^{*} \\
(59- \\
101.25) \\
{[50-111]}\end{array}$ & $\begin{array}{c}98.5^{*} \\
(70.75- \\
106.75) \\
{[58-112]} \\
\end{array}$ \\
\hline во клеток & $\begin{array}{c}7 \\
(4.75-8.5) \\
{[4-10]}\end{array}$ & $\begin{array}{c}7 \\
(4.75-9) \\
{[4-9]}\end{array}$ & $\begin{array}{c}4.5^{*} \\
(3.5-5.5) \\
{[2-7]}\end{array}$ & $\begin{array}{c}2^{*} \\
(1.75-2) \\
{[1-2]}\end{array}$ & $\begin{array}{c}2^{*} \\
(0.75-2.25) \\
{[0-3]}\end{array}$ & $\begin{array}{c}1^{*} \\
(0-1 \\
{[1-1]}\end{array}$ & $\begin{array}{c}1.5^{*} \\
(1-2.25) \\
{[1-3]}\end{array}$ & $\begin{array}{c}2^{*} \\
(1.5-2.5) \\
{[0-4]}\end{array}$ \\
\hline $\begin{array}{l}\text { еток } \\
\text { ра }\end{array}$ & $\begin{array}{c}4 \\
(2.75- \\
10.25) \\
{[2-11]} \\
\end{array}$ & $\begin{array}{c}10 \\
(6.13-13.5) \\
{[6-15]}\end{array}$ & $\begin{array}{c}30^{*} \\
(29.5- \\
32.75) \\
{[28-35]}\end{array}$ & $\begin{array}{c}23.5^{*} \\
(17.5-29) \\
{[16-32]} \\
\end{array}$ & $\begin{array}{c}15^{*} \\
(10.25-18) \\
{[8-18]} \\
\end{array}$ & $\begin{array}{c}21^{*} \\
(17.75- \\
23.25) \\
{[17-24]}\end{array}$ & \begin{tabular}{|c|}
$16.5^{*}$ \\
$(12.5-18)$ \\
\\
{$[11-18]$} \\
\end{tabular} & $\begin{array}{c}24^{*} \\
(20.75- \\
30.5) \\
{[20-32]}\end{array}$ \\
\hline $\begin{array}{l}\text { Количество клеток } \\
\text { с апоптотическим } \\
\text { тельцами }\end{array}$ & $\begin{array}{c}4.5 \\
(1.75-7.5) \\
{[1-9]}\end{array}$ & $\begin{array}{c}1.5 \\
(1-2.25) \\
{[1-3]}\end{array}$ & $\begin{array}{c}1^{*} \\
(0.75-2.25) \\
{[0-3]}\end{array}$ & $\begin{array}{l}0.5^{*} \\
(0-1) \\
{[0-1]}\end{array}$ & $\begin{array}{c}1^{*} \\
(0-1) \\
{[1-1]}\end{array}$ & $\begin{array}{c}0.5^{*} \\
(0-1.25) \\
{[0-2]}\end{array}$ & $\begin{array}{c}0.5^{*} \\
(0-1.25) \\
{[0-2}\end{array}$ & $\begin{array}{c}1 \\
(0.75-3.25) \\
{[0-4]}\end{array}$ \\
\hline \multicolumn{9}{|c|}{ Экстракт зеленого чая } \\
\hline $\begin{array}{l}\text { клеток } \\
\text { ния }\end{array}$ & $\begin{array}{c}155.5 \\
(137.5- \\
167.5) \\
{[133-169]} \\
\end{array}$ & $\begin{array}{c}152.5 \\
(136- \\
162.75) \\
{[133-165]} \\
\end{array}$ & $\begin{array}{c}149 \\
(141-153) \\
{[138-156]} \\
\end{array}$ & $\begin{array}{c}121 \\
(121- \\
136.75) \\
{[95-139]} \\
\end{array}$ & $\begin{array}{c}110^{*} \\
(106.25- \\
127.25) \\
{[104-137]} \\
\end{array}$ & \begin{tabular}{|c|}
128 \\
$(109-136)$ \\
{$[106-139]$} \\
\end{tabular} & \begin{tabular}{|c|}
124.5 \\
$(117.75-$ \\
$131.75)$ \\
{$[114-137]$} \\
\end{tabular} & $\begin{array}{c}116^{*} \\
(109.25- \\
122.25) \\
{[104-129]} \\
\end{array}$ \\
\hline $\begin{array}{l}\text { Количество } \\
\text { мертвых клеток в } \\
\text { поле зрения }\end{array}$ & $\begin{array}{c}5.5 \\
(3.5-6.75) \\
{[2-9]}\end{array}$ & $\begin{array}{c}13.5 \\
(10-15.5) \\
{[4-17]}\end{array}$ & $\begin{array}{c}9.5 \\
(2.75-14) \\
{[2-17]}\end{array}$ & $\begin{array}{c}10^{*} \\
(7.75-12.25) \\
{[4-15]}\end{array}$ & $\begin{array}{c}5.5 \\
(4-8.25) \\
{[4-12]}\end{array}$ & $\begin{array}{c}13^{*} \\
(10-17.25) \\
{[10-18]}\end{array}$ & $\begin{array}{c}4 \\
(3-7.25) \\
{[3-11]}\end{array}$ & $\begin{array}{c}6.5 \\
(5.75-8.25) \\
{[5-9]}\end{array}$ \\
\hline $\begin{array}{l}\text { Количество живых } \\
\text { клеток в поле } \\
\text { зрения }\end{array}$ & $\begin{array}{c}149.5 \\
(136.25- \\
165) \\
{[128-165]} \\
\end{array}$ & $\begin{array}{c}136.5 \\
(121.25- \\
154.25) \\
{[116-158]} \\
\end{array}$ & $\begin{array}{c}135.5 \\
(130.75- \\
150.25) \\
{[130-154]} \\
\end{array}$ & $\begin{array}{c}107.5 \\
(90- \\
127.75) \\
{[84-130]} \\
\end{array}$ & $\begin{array}{c}104.5 \\
(99.25- \\
116.75) \\
{[97-131]} \\
\end{array}$ & \begin{tabular}{|c|}
113.5 \\
$(99-119.5)$ \\
{$[96-124]$} \\
\end{tabular} & \begin{tabular}{|c|}
119 \\
$(114.75-$ \\
$126.25)$ \\
{$[111-127]$} \\
\end{tabular} & $\begin{array}{c}120 \\
(107.25-123) \\
{[95-123]} \\
\end{array}$ \\
\hline $\begin{array}{l}\text { Количество клеток } \\
\text { с серпами }\end{array}$ & $\begin{array}{c}7 \\
(4.75-8.5) \\
{[4-10]}\end{array}$ & $\begin{array}{c}3 \\
(2-3.25) \\
{[2-4]}\end{array}$ & $\begin{array}{c}1^{*} \\
(0-2.25) \\
{[0-3]}\end{array}$ & $\begin{array}{c}1^{*} \\
(0-1.25) \\
{[0-2]}\end{array}$ & $\begin{array}{c}2.5^{*} \\
(1.75-4) \\
{[1-4]}\end{array}$ & $\begin{array}{c}3.5 \\
(2-4.5) \\
{[2-6]}\end{array}$ & $\begin{array}{c}4 \\
(3-5) \\
{[3-5]}\end{array}$ & $\begin{array}{c}3 \\
(2.75-4) \\
{[2-4]}\end{array}$ \\
\hline $\begin{array}{l}\text { Количество клеток } \\
\text { с пикнозом ядра }\end{array}$ & $\begin{array}{c}4 \\
(2.75-10.25) \\
{[2-11]} \\
\end{array}$ & $\begin{array}{c}4.5 \\
(3.75-5.25) \\
{[3-6]} \\
\end{array}$ & $\begin{array}{c}3.5 \\
(0.75-4.25) \\
{[0-5]}\end{array}$ & $\begin{array}{c}2^{*} \\
(0-3) \\
{[0-3]} \\
\end{array}$ & $\begin{array}{c}2.5 \\
(1-3.5) \\
{[1-5]} \\
\end{array}$ & $\begin{array}{c}3 \\
(2.75-4) \\
{[2-4]} \\
\end{array}$ & $\begin{array}{c}5.5 \\
(3.5-6.5) \\
{[2-8]} \\
\end{array}$ & $\begin{array}{c}3.5 \\
(2.75-4.5) \\
{[2-5]} \\
\end{array}$ \\
\hline $\begin{array}{l}\text { Количество клеток } \\
\text { с апоптотическими } \\
\text { тельцами }\end{array}$ & $\begin{array}{c}4.5 \\
(1.75-7.5) \\
{[1-9]}\end{array}$ & $\begin{array}{c}0 \\
(0-0.25) \\
{[0-1]}\end{array}$ & $\begin{array}{c}0 \\
(0-0.25) \\
{[0-1]}\end{array}$ & $\begin{array}{c}0 \\
(0-0) \\
{[0-0]}\end{array}$ & $\begin{array}{c}0 \\
(0-0.25) \\
{[0-1]}\end{array}$ & $\begin{array}{c}2.5 \\
(0-4.25) \\
{[0-5]}\end{array}$ & $\begin{array}{c}1.5 \\
(0-4.5) \\
{[0-6]}\end{array}$ & $\begin{array}{c}0^{*} \\
(0-0.25) \\
{[0-1]}\end{array}$ \\
\hline
\end{tabular}

Примечание. * Достоверность различий между контрольной и экспериментальной группами, рассчитанная при помощи критерия Манна-Уитни, $p<0.05$. 

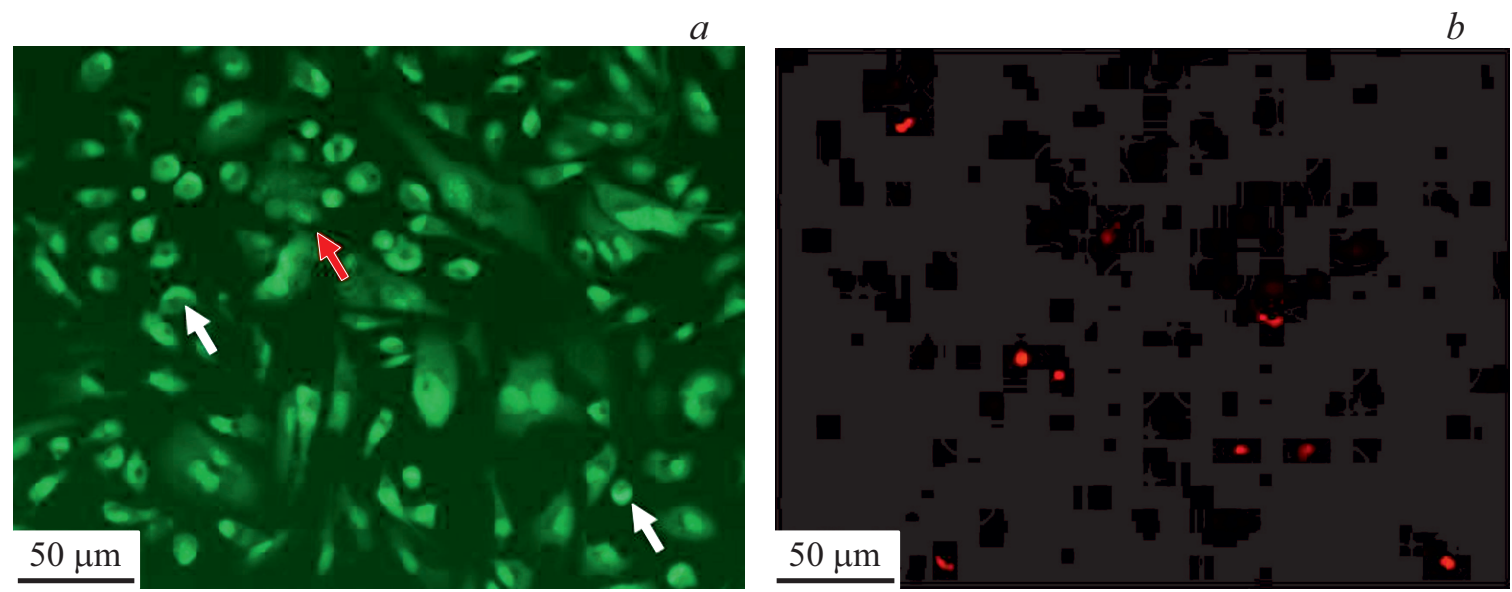

Рис. 2. Клетки культуры A498 через $24 \mathrm{~h}$ после инкубации с экстрактом аврана лекарственным в концентрации $0.0018 \mathrm{mg} / \mathrm{ml}$ : $a$ - окраска акридиновым оранжевым хроматина ядер живых клеток (белой стрелкой указаны ядра по типу серпов, красной стрелкой - апоптотические тельца), $b$ - окраска мертвых клеток йодистым пропидием. Обьектив $\times 20$.
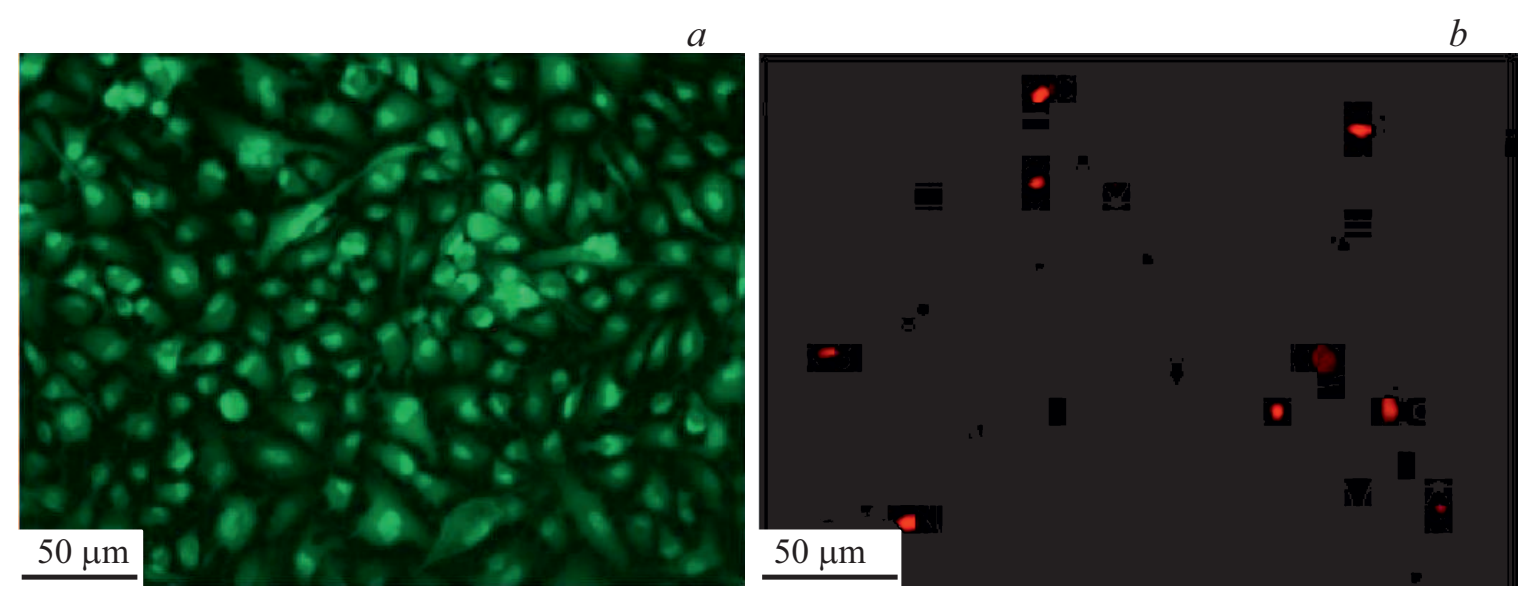

Рис. 3. Клетки культуры A498 через $24 \mathrm{~h}$ после инкубации с экстрактом аврана лекарственным в концентрации $0.0018 \mathrm{mg} / \mathrm{ml}: a-$ окраска акридиновым оранжевым хроматина ядер живых клеток, $b-$ окраска мертвых клеток йодистым пропидием. Обьектив $\times 20$.

ях $0.0036,0.0144,0.0576,0.1152 \mathrm{mg} / \mathrm{ml}$. При концентрации $0.0144 \mathrm{mg} / \mathrm{ml}$ количество клеток максимально увеличивается по сравнению с контролем в 4.5 раза.

Под действием экстракта зеленого чая количество клеток с ядрами по типу серпа увеличиваются по сравнению с контролем достоверно только при концентрациях 0.0018 и $0.0072 \mathrm{mg} / \mathrm{ml}$, а ядра в состоянии пикноза - при концентрациях 0.0018 и $0.0576 \mathrm{mg} / \mathrm{ml}$. Апоптотические тельца не выявлены при действии экстракта из зеленого чая (табл. 1 , рис. 3 ).

В ходе проведения флуоресцентной микроскопии через $48 \mathrm{~h}$ воздействия экстрактом аврана установлено уменьшение общего количества клеток при концентрациях выше $0.0018 \mathrm{mg} / \mathrm{ml}$ по сравнению с контрольной группой. Максимальное уменьшение общего количества клеток в 2 раза наблюдали при концентрации $0.0576 \mathrm{mg} / \mathrm{ml}$ по сравнению с контролем (табл. 2).
Также уменьшение общего числа клеток наблюдалось при воздействии экстракта зеленого чая, но только при двух концентрациях 0.0144 и $0.1152 \mathrm{mg} / \mathrm{ml}$ (табл. 2).

При воздействии экстракта аврана лекарственного в концентрациях $0.0036-0.0144 \mathrm{mg} / \mathrm{ml}$ наблюдали увеличение в 2 раза количества мертвых клеток по сравнению с контролем, тоже при действии экстракта зеленого чая $(0.0144,0.1152 \mathrm{mg} / \mathrm{ml})$, что свидетельствует о появлении цитотоксической активности данных веществ на вторые сутки исследования (табл. 2).

Количество клеток рака почки с ядрами в виде серпов, пикнозом ядер и апоптотическими тельцами достоверно увеличивалось через $48 \mathrm{~h}$ под действием экстракта аврана по сравнению с контролем, начиная с концентрации $0.0036 \mathrm{mg} / \mathrm{ml}$. Однако преобладали клетки с пикнозом ядра до $20 \%$ от общего количества (табл. 2).

Под действием флавоноидов зеленого чая количество клеток рака почки с ядрами в виде серпов, пикнозом 
ядер достоверно увеличивалось через $48 \mathrm{~h}$ только при единичных концентрациях $0.0018,0.0072$ и $0.0576 \mathrm{mg} / \mathrm{ml}$. Апоптотические тельца под действием экстракта зеленого чая не образовывались и через 48 h (табл. 2).

\section{Обсуждение}

Наиболее выраженной цитостатической активностью обладал экстракт аврана через $48 \mathrm{~h}$ после воздействия на опухолевые клетки по сравнению с контрольной группой, уменьшая количество клеток в поле зрения в 1.5 раза по сравнению с контролем. Появление цитостатической активности только через $48 \mathrm{~h}$ и отсутствие через $24 \mathrm{~h}$ после воздействия могло свидетельствовать о медленном процессе воздействия активных веществ экстракта на регуляцию клеточного цикла.

Наиболее выраженной цитотоксической активностью обладал экстракт зеленого чая в концентрации $0.0288 \mathrm{mg} / \mathrm{ml}$, причем выраженность этой активности нарастала через $48 \mathrm{~h}$ после воздействия. Экстракт аврана проявлял такую активность при более низких концентрациях, начиная с концентрации $0.0036 \mathrm{mg} / \mathrm{ml}$.

Наибольшей апоптотической активностью обладал экстракт аврана, вызывая в значительной степени пикноз ядер клеток рака почки при всех концентрациях как через 24, так и $48 \mathrm{~h}$ после воздействия. Это свидетельствует об активации ранних стадий апоптоза. Однако при воздействии экстрактом аврана наблюдали и клетки с ядрами в виде серпов и более позднюю стадию апоптоза - апоптотические тельца. Экстракт зеленого чая проявлял очень слабую апоптотическую активность через $24 \mathrm{~h}$ и совсем не проявлял ее через $48 \mathrm{~h}$.

Полученные данные свидетельствуют о том, что катехины зеленого чая в сверхнизких концентрациях не оказывают существенного влияния на клеточный цикл и активацию путей апоптоза опухолевых клеток рака почки, что показало их неэффективность в эксперименте in vitro. Однако в литературных данных отражены результаты исследований in vivo, где под влиянием катехинов наблюдается замедление развития опухоли в результате снижения васкуляризации и соответственно питания клеток, что способствует их деградации и гибели. В более высоких концентрациях $(0.5 \mathrm{mg} / \mathrm{ml})$ начинают проявляться и реализовываться механизмы блокировки канцерогенеза, описанные ранее [12]. Экстракт аврана показал свою эффективность при сверхнизких концентрациях.

\section{Выводы}

Таким образом, использование флуоресцентных методов в тесте „живые и мертвые“ позволило визуализировать клетки с различными механизмами гибели и выявить пути гибели клеток карциномы почки человека А498 под действием экстракта аврана лекарственного и флавоноидов зеленого чая. Так, у экстракта аврана преобладающим путем гибели клеток культуры рака почки А498 является апоптоз через $24 \mathrm{~h}$ и апоптоз и некроз через $48 \mathrm{~h}$. У флавоноидов зеленого чая как через $24 \mathrm{~h}$, так и $48 \mathrm{~h}$ преобладающим путем гибели клеток рака почки является некроз.

\section{Финансирование работы}

Исследование выполнено при финансовой поддержке РФФИ в рамках научного проекта № 18-015-00298, а также в рамках государственного задания Минздрава России „Исследование экстрактов лекарственных растений, содержащих флавоноиды, и их фракций с целью создания препаратов, обладающих противоопухолевой, антиоксидантной, антикахексической и другой активностьюб.

\section{Соблюдение этических стандартов}

Настоящая работа не содержит каких-либо исследований с участием людей в качестве объектов исследования.

\section{Конфликт интересов}

Авторы заявляют, что у них нет конфликта интересов.

\section{Список литературы}

[1] Kharkevich D.A. Pharmacology: Textbook. 10th ed. M.: GEOTAR-Media, 2008. 750 p.; Харкевич Д.А. Фармакология: Учебник. 10-е изд. М.: ГЭОТАР-Медиа, 2008. 750 с.

[2] Векшин Н.Л. Флуоресцентная спектроскопия биополимеров. Пущино: Фотон-век, 2009. 168 с.

[3] Stepanenko O.V., Kuznetsova I.M., Turoverov K.K., Verkhusha V.V. // Cytology. 2007. V. 49. N 5. P. 395.

[4] Cassimeris L., Lingappa V.R., Plopper G. Lewin's Cells. Jones and Bartlett Publishers, 2011. 1056 p.; Кассимерис L., Лингапnа B.P., Плоппер Джс.. Клетки по Льюину. М.: Лаборатория знаний, 2016. $1056 \mathrm{c}$.

[5] Drummen G.P.C. // Molecules. 2012. V. 17. P. 14067. doi 10.3390/molecules 171214067

[6] Udenfriend S. // Pr. Sc. 2015. V. 4. N 3. P. 542. doi 10.1002/pro.5560040321

[7] Galluzzi L., Vitale I., Abrams J M. etal. // Cell Death Differ. 2012. V. 19. N 1. P. 107. doi $10.5167 /$ uzh-4928

[8] Navolokin N.A., Polukonova N.V., Mudrak D.A. etal. // Opt. Spectrosc. 2019. V. 126. N 6. P. 773.

[9] Korman D.B. Basics of Antitumor Therapy. M.: Practical medicine, 2006. 512 р.; Корман Д.Б. Основы противоопухолевой терапии. М.: Практическая медицина, 2006. 512 с.

[10] Du G.J, Zhang Z., Wen X.D. // Nutr. 2012. V. 4. N 11. P. 1679.

[11] Поверим А.Д. // Пищевая промышленность. 2008. № 7. C. 36.

[12] Pan M.H., Chiou Y.S., Wang Y.J. // Food Funct. 2011. N 2. P. 101.

[13] Полуконова А.В., Дурнова Н.А., Курчатова М.Н., Наволокин Н.А., Голиков А.Г. // Химия растительного сырья. 2013. № 4. C. 165 . doi $10.14258 /$ jcprm. 1304165

[14] Navolokin N.A., Polukonova N.V., Maslyakova G.N. // ROMJ. 2012. V. 1. N 2. P. 203. 
[15] Navolokin N.A., Mudrak D.A., Polukonova N.V. // Exp. And Clin. Pharm. 2017. V. 80. N 6. P. 19. doi 10.30906/0869-20922017-80-6-19-23

[16] Navolokin N.A., Mudrak D.A., Bucharskaya A.B., Matveeva O.V., Tychina S.A., Polukonova N.V., Maslyakova G.N. // ROMJ. 2017. V. 6. N 3. P. 304.

[17] Navolokin N.A., Ivlichev A.V., Mydrak D.A., Afanasjeva G.A. // Eksp. and Klin. Farm. 2017. V. 80. N 10. P. 40. doi 10.30906/0869-2092-2017-80- 10-40-43

[18] Polukonova N.V., Kurchatova M.N., Navolokin N.A., Bucharskaja A.B., Durnova N.A., Maslyarkova G.N. // ROMJ. 2014. V. 3. P. 0304. doi 10.15275/rusomj.2014.0304

[19] Tkachenko N., Pravdin A., Terentjuk G., Navolokin N., Kurchatova M., Polukonova N.V. // Proc. SPIE. 2015. V. 9448. P. 94480. doi 10.1117/12.2179862

[20] Tkachenko N.V., Bykova E.V., Pravdin A.B., Navolokin N.A., Polukonova N.V., Bucharskaja A.B. // Proc. SPIE. 2016. V. 9917. P. 99170. doi 10.1117/12.2228291, doi 10.15275/rusomj.2017.0304

[21] Navolokin N.A., Skvortsova V.V., Polukonova N.V., Manaenkova E.V., Pankratova L.E., Kurchatova M.N., Maslyakova G.N., Durnova N.A. // Eksp. and Klin. Farm. 2015. V. 78. P. 10. doi 10.30906/0869-2092-2015-78-4-10-13

[22] Polukonova N.V., Navolokin N.A., Raykova S.V.// Eksp. and Klin. Farm. 2015. V. 78. N 1. P. 34. doi 10.30906/0869-20922015-78-1-34-38

[23] Navolokin N.A., Maslyakova G.N., Polukonova N.V. // Arch. of Path. 2019. V. 81. N 1. P. 24. 